Psicologia Escolar

e Educacional
ARTIGO

DOI: http://dx.doi.org/10.1590/2175-35392021223958

Localizador - e223958

\title{
A FORMAÇÃO DOCENTE DIANTE DE PROJETOS SIGNIFICATIVOS PARA ALUNAS DO ENSINO MÉDIO
}

\author{
Fabrício Ofugi ${ }^{1} \mathbb{D}$
}

\section{RESUMO}

Este artigo tem como objetivo apresentar o relato de uma prática profissional de um professor que resultou em uma apresentação musical de estudantes do Ensino Médio junto a um renomado grupo musical. A realização dessa prática aconteceu no contexto de reflexão sobre a prática docente entre professores do Ensino Médio no Instituto Federal de Brasília. Diante da reflexão, inspirados pela teoria fundamentada, buscou-se a geração de dados a partir de escutas em sala de aula que contribuíram para a realização de projetos que trouxessem significados para os alunos. O relato traz as etapas para a realização desses projetos. O resultado dessa experiência evidenciou a necessidade de abordagens efetivas da Psicologia na formação docente no contexto da interação com estudantes do Ensino Médio.

Palavras-chave: formação de professores; ensino médio; psicologia.

\section{Teacher formation and the development of relevant projects for female high school students}

\begin{abstract}
This article aims to present the account of a professional practice by a teacher that resulted in a musical presentation by high school students with a renowned musical group. This practice took place in the context of reflection on teaching practice among high school teachers at the Federal Institute of Brasília. In the face of reflection, inspired by grounded theory, we sought to generate data from listening in the classroom that contributed to the realization of projects that brought meaning to students. The report provides the steps for carrying out these projects. The result of this experience showed the need for effective approaches to Psychology in teacher education in the context of interaction with high school students.
\end{abstract}

Keywords: Teacher training; High school; Psychology.

\section{La formación docente delante de proyectos significativos para alumnas de la Enseñanza Secundaria}

\section{RESUMEN}

En este artículo se tiene como objetivo presentar el relato de una práctica profesional de un profesor que resultó en una presentación musical de estudiantes de la Enseñanza Secundaria junto a un renombrado grupo musical. La realización de esa práctica sucedió en el contexto de reflexión sobre la práctica docente entre profesores de lo Enseñanza Secundaria en el Instituto Federal de Brasília. Delante de la reflexión, inspirados por la teoría fundamentada, se buscó la generación de datos a partir de escuchas en sala de clase que contribuyeron para la realización de proyectos que trajeron significados para los alumnos. El relato trae las etapas para la realización de esos proyectos. El resultado de esa experiencia evidenció la necesidad de abordajes efectivos de la Psicología en la formación docente en el contexto de la interacción con estudiantes de la Enseñanza Secundaria.

Palabras clave: formación de profesores; enseñanza secundaria; psicología.

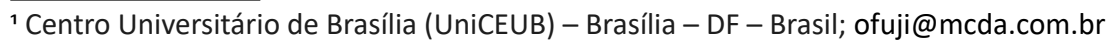




\section{INTRODUÇÃO}

No dia 13 de maio de 2018, aconteceu em Brasília uma apresentação musical exclusiva em festival musical. Nessa ocasião, a banda Francisco, el Hombre contou com a participação de um coral feminino para interpretar a música Triste, Louca ou Má. O fato relevante é que esse coral foi formado por estudantes do Ensino Médio. Assim, este artigo é um relato sobre a prática docente e tem como objetivo apresentar as etapas para a realização dessa apresentação e levantar problemas relativos à formação dos professores.

A proposta dessa performance artística emergiu a partir de um processo de reconfiguração de nossa prática docente e foi baseado em conversas com estudantes nas diferentes aulas dos cursos técnicos em Eventos do Instituto Federal de Brasília (IFB). A ação teve como justificativa o discurso comum das alunas sobre a falta de espaço na escola para a prática de atividades que fizessem "mais sentido" e teve como motivação o papel do Ensino Médio enquanto espaço para construção de projetos de vida (Weller \& Gauche, 2017).

Nesse relato, utilizaremos a primeira pessoa no plural em virtude da importância das múltiplas participações que viabilizaram essa experiência: as alunas, outras docentes, os artistas e as pessoas ligadas à organização do festival musical. Enquanto resultado desse projeto, concordamos sobre a necessidade da Psicologia para a formação docente no Ensino Médio (Almeida, Alves, Neves, Silva, \& Pedroza, 2007).

A seguir, organizamos esse texto da seguinte maneira. Primeiramente, apresentaremos o contexto escolar no qual os participantes dessa experiência estavam inseridos. Todo esse processo foi resultado de um projeto de ensino (IFB em Transição) cujo objetivo era promover a implementação de algumas ações presentes no Projeto Pedagógico do Curso (PPC) Técnico em Eventos Integrado ao Ensino Médio do IFB (Resolução № 021/2015/CS-IFB), a partir do uso de metodologia de aprendizagem baseada em projetos (Queiroz, 2018).

Em seguida, descreveremos o conjunto de ações adotadas pelo professor na tentativa de reconfigurar sua prática docente. A metodologia adotada para a realização desse projeto cultural, o canto coral das estudantes junto a um grupo musical renomado, inspirou-se na teoria fundamentada de Corbin e Strauss (2008), sobretudo no que diz respeito às características do pesquisador. Por fim, a partir da percepção docente sobre a importância de estudos da Psicologia, apresentaremos alguns resultados e encaminhamentos.

\section{CONTEXTO E MÉTODO}

A experiência do projeto de ensino ao qual nos referimos anteriormente está presente em artigo da professora Alice Watson Queiroz (2018) sobre os relatos integradores exitosos da rede dos institutos federais.
Motivados por uma proposta liderada pelo educador português José Pacheco, um grupo de cinco docentes participou de uma formação chamada Escolas em Transição. Essa formação motivou a criação de um conjunto maior de professores do colegiado do curso técnico em eventos integrado ao ensino médio (CTEIEM) para discutir sua prática pedagógica e a execução plena de seu respectivo PPC com base no uso de metodologia de aprendizagem baseada em projetos.

No primeiro semestre de 2017, em uma primeira etapa, os professores realizaram estudos e encontros com o educador Pacheco para atuarem enquanto orientadores de grupos de estudantes. Assim, teriam como atribuição orientar esses alunos sobre o planejamento de um projeto cujos objetivos se relacionassem aos conteúdos de aprendizagem segundo as diretrizes do ensino médio, ao PPC e também aos interesses pessoais de cada envolvido. Depois, durante um período de dois meses (no fim de 2017), em horário contraturno, executaram projeto piloto com 10 estudantes. Por fim, para o ano seguinte, determinaram em conjunto ao colegiado de curso, a definição de um dia da semana para atividades em grupos orientados por determinados professores.

Nesse mesmo período de estudos e execução de projetos de ensino, que compreende os anos de 2017 e 2018, realizamos uma pesquisa com base na geração de dados a partir da escuta sobre projetos significativos aos estudantes. Como veremos a seguir, todo o contexto descrito acima contribuiu para que outras práticas pudessem ser experimentadas em sala de aula.

\section{A escuta em sala de aula}

Em um dos momentos com o educador José Pacheco, tivemos a recomendação de que deveríamos buscar mais inspiração no Projeto Âncora (escola em Cotia, no estado de São Paulo) e menos na Escola da Ponte (Portugal). Na ocasião, Pacheco disse algo como: lá na escolinha (Ponte), seguimos mais a intuição. No Âncora, tivemos uma maior sistematização - ao citar a importância de estudar o projeto político pedagógico das escolas.

Essa fala assumida a partir dessas duas experiências do educador nos direcionou a um referencial metodológico inspirado na teoria fundamentada de Corbin e Strauss (2008). Entre as características necessárias ao pesquisador, os autores especificam a intuição e sensibilidade. Nessa inspiração por aplicar alguns princípios da metodologia, concordamos que problemas de pesquisa devem emergir a partir dos dados gerados em sala de aula. Assim, independentemente das disciplinas que lecionávamos, abrimos espaço para ouvir os estudantes.

Coincidentemente, um tema que emergiu dentro do processo de criação de atividades que tivessem relevância em todas as turmas se referia ao papel da mulher na sociedade. Para ilustrar, citaremos duas ocorrências. Em 
uma disciplina de organização de eventos para o curso técnico subsequente em eventos, as alunas trouxeram como tema de realização de projeto, o combate ao machismo no campus. Elas compartilharam que haviam realizado uma pesquisa quantitativa no semestre anterior cujos dados registravam que mais de $60 \%$ das estudantes abordadas sofreram ou testemunharam atos considerados machistas.

Nas turmas de ensino médio, ao planejarem um evento sobre diversidade, propusemos que os estudantes elaborassem algumas perguntas que os incomodavam. Surgiram questões sobre orientação sexual, divergência religiosa e, majoritariamente, sobre o incômodo sofrido cotidianamente em relação a atitudes de assédio recebidas. Logo, assumimos a importância de abordar, de alguma maneira, questões relativas a gênero.

Como o tempo dedicado aos estudos para aprofundamento da temática era escasso, em um primeiro momento incentivamos essas estudantes a criarem um projeto para inscrição em edital interno dedicado aos discentes para apoio a eventos culturais - o Programa de Incentivo à Cultura, Esporte e Lazer (PINCEL). Assim, o projeto intitulado "Quem tem boca vem pra roda" foi beneficiado pelo programa e realizado por alunas de ambos os cursos.

De forma resumida, podemos dizer que esse projeto foi composto por um conjunto de ações - roda de conversa e oficina de escrita criativa - focados no público feminino e que tinha como objetivo promover o seu empoderamento. Essas ações e interações promovidas por elas as conduziram à escolha da música Triste, Louca ou Má enquanto tema dessas ações. Essa foi a música que o coral feminino viria interpretar junto à banda responsável por sua composição - conforme mencionamos no início desse artigo. A importância da música nesse contexto pode ser resumida por seu refrão: $O$ homem não te define/ sua casa não te define/ Você é seu próprio lar.

Toda a reflexão produzida por esse projeto contribuiu para a elaboração de alguns problemas de pesquisa: (a) diante de questões como essas, de natureza feminista, o professor (compreendendo aqui qualquer docente do sexo masculino e independentemente da disciplina ministrada) está apto para abordar o tema? (b) Se mesmo tendo estudado a temática, temos o conjunto de conhecimentos e práticas necessárias para a abordagem mais adequada? (c) Assim, qual seria a abordagem mais adequada?

Essas questões levantadas pelas estudantes sobre gênero e o papel da escola em suas vidas nos provocaram uma inquietação diante do contexto promovido pelo projeto IFB em Transição ao promover a aprendizagem por meio de projetos (Queiroz, 2018). Entre as realizações, tínhamos realizado a orientação de um projeto (Quem tem boca vem pra roda) que contribuiu para que as alunas pudessem discutir e produzir textos a partir de sua percepção feminina. No entanto, sentíamos falta de algo que articulasse a escola e a comunidade. De acordo com alguns estudos sobre juventude, refletimos sobre a definição de competências da adolescência (Calligaris, 2000).

A partir da emergência dessa questão, contamos com uma convergência de fatores que contribuíram para a produção dessa apresentação musical que tinha como propósito trabalhar a construção de ações significativas para os jovens. Descreveremos, assim, toda a trajetória que se inicia com uma apresentação do coral da escola em atividade de encerramento do primeiro semestre letivo de 2017.

\section{Sobre apresentação do coral}

Durante essa apresentação do coral no encerramento do semestre, foi perceptível os sentimentos ali provocados. Havia uma dezena de professores chorando, demonstrando sua emoção. Esse momento nos marcou e, inclusive, indicou que podemos, futuramente, realizar pesquisas com grupos corais enquanto desdobramento desse relato de prática pedagógica.

No segundo semestre de 2017, não houve atividades do coral em virtude de licença médica da professora de música, Rita Mendonça. Porém, nos diálogos estabelecidos em sala de aula, percebemos que algumas pessoas que fizeram parte daquele coral, mantinham contato e a vontade por continuarem essa prática. O primeiro semestre de 2018 iniciou-se; porém, a professora não retomou as atividades do coral. Em primeiro momento, alegou que não conseguiu aprovação como projeto de extensão.

Em março, por meio da organização do festival musical Móveis Convida (que acontece em Brasília desde 2005 e que recebeu essa performance), soubemos que a banda Francisco, el Hombre seria uma das atrações. Seguimos nossa intuição e, diante dessa informação, reunimos a lembrança sobre as possibilidades de emocionar a partir de um canto coral, o tema musical definido pelas estudantes naquele projeto de roda de conversa feminina e a inquietação por projetos significativos para estudantes de curso técnico em eventos.

A partir dessa ideia, buscamos verificar sua relevância (artística e significativa) junto às estudantes, à organização do evento, à professora do coral e aos artistas. Vale mencionar que usamos a nossa experiência profissional no mercado musical e o fato de ministrar aulas de disciplinas da área técnica de eventos para que houvesse essa proposta. Depois de validada por cada uma dessas pessoas, tivemos os seguintes passos estabelecidos (para realização entre março e abril de 2018 - uma vez que a apresentação seria no mês de maio): reativar a prática do coral, ensaiar a música, enviar uma gravação ao grupo, estabelecer comunicação 
entre grupo e coral, produzir a participação do coral (no sentido de obter autorizações para a entrada de pessoas menores de 18 anos no evento, organizar horário de ensaio com o grupo, entre outras atribuições).

As estudantes que participaram do projeto Quem tem boca, vem pra roda foram as primeiras a terem ciência dessa ideia. Nosso intuito foi provocar a sua mobilização para atuação junto à professora de música para restabelecimento das atividades do coral. Estimulamos também aquelas estudantes que não participavam do coral e nem do projeto mas que partilhavam a vontade de desenvolver projetos que julgavam relevantes nessa perspectiva do lugar da mulher.

Coincidentemente, no mesmo dia em que iniciamos as conversas com as alunas, ao acaso conseguimos também conversar com a professora Rita Mendonça. Na ocasião, as alunas tentaram contato telefônico, mas não tiveram êxito. No entanto, pudemos encontrá-la na saída do campus ao acaso. Outra coincidência contribuiu para o êxito da proposta - a professora, durante essa conversa, afirmou que junto a um coletivo feminino, ensaiava a música Triste, Louca ou Má.

Esses encontros aconteceram no meio da semana, em uma quarta-feira e, para nossa satisfação, na segunda-feira seguinte, o coral estava ensaiando, ainda que sem contabilizar carga horária oficial para a professora e estudantes participantes.

Como essa proposta foi apoiada por todas as pessoas envolvidas (da organização do evento ao grupo artístico), logo se desencadearam todas as etapas necessárias. A gravação do vídeo de um ensaio do coral, o aceite do grupo e seu devido contato com a professora de música. Tudo isso devidamente alinhado com a organização do festival e as famílias das estudantes (que, consequentemente, autorizaram sua participação).

A apresentação foi registrada e lançada em videoclipe que pode ser visto no canal do grupo musical na internet lançado em julho de 2018. Nas redes sociais, a vocalista do grupo, Juliana Strassacapa, enalteceu a parceria e estimulou as jovens a fazerem de seus sonhos sua ousadia. É possível assistir ao videoclipe ${ }^{1}$.

\section{CONSIDERAÇÕES FINAIS}

Uma série de fatores foi fundamental para que uma ação dessa natureza acontecesse. O envolvimento com um grupo musical renomado (para ilustrar, vale lembrar que a música em questão, à época havia sido tema de personagem de telenovela, que inclusive discutia a violência contra a mulher) contribuiu para que cada etapa acontecesse com maior motivação. O videoclipe da música possui mais de 100 mil visualizações e continua gerando comentários sobre a relevância da música e/

${ }^{1}$ Disponível em https://youtu.be/jLxxstrxkLI acesso em 9 de maio de 2019 ou da participação do coral. Conseguimos, conforme este relato, produzir projetos significativos para as estudantes. Por outro lado, isso evidenciou uma série de carências por parte dos docentes.

Assim, do ponto de vista acadêmico, essa prática contribuiu para a exposição e levantamento de problemas. O primeiro diz respeito à existência de espaço de convergência de ações educativas formais fora do ambiente escolar. Assim, cabe problematizar o papel social do Ensino Médio.

Além disso, como dito anteriormente, nos guiamos sobre a reflexão do papel docente e a importância da Psicologia em sua formação. $E$, aqui, concordamos com Piaget (1979) a partir de um de seus interlocutores no Brasil, citado por Lauro de Oliveira Lima (1979) sobre a Psicologia ser fundamental para o professor. Assim, surgem questões que vão além das abordagens de disciplinas de Psicologia escolar e desenvolvimento humano em cursos de licenciatura. Diante dos desafios que surgem em sala, falta o amparo necessário na formação do professor (Almeida et al., 2007) e também vale questionar sobre o interesse em sua formação continuada. Neste caso, utilizamos a criação de projetos como uma solução para abordagem de questões às quais não tínhamos o devido conhecimento.

Para outros estudos, a proposta de estabelecer alguns princípios da teoria fundamentada nos evidenciou a necessidade de aprofundamentos em questões sobre a adolescência e sua relação com a sociedade. Procuramos nessa experiência, não tratar a adolescência como algo natural e passageiro conforme uma concepção percebida por Bock e Liebesny (2003). Tampouco nos omitimos de usar a sala de aula para promover a interação e o contato com o cotidiano das estudantes (Pedroza, 2005). Ciente desse potencial cenário de problemas e dados, vale a reflexão para o uso desse relato enquanto um motivador para futuras pesquisas que possam contribuir com a formação docente.

\section{REFERÊNCIAS}

Almeida, R. S.; Alves, C. B.; Neves, G. N.; Silva, L. P.; Pedroza, R. L. S. (2007). O professor de ensino médio e a psicologia em seu cotidiano escolar. Psicologia Escolar e Educacional, v. 11 , p. $123-132$

Bock, A. M. B.; Liebesny, B. (2003). Quem eu quero ser quando crescer: um estudo sobre projeto de vida de jovens em São Paulo. In: Ozella, S. (ed.), Adolescências construídas: a visão da psicologia sócio-histórica. São Paulo: Cortez.

Calligaris, C. (2009). A adolescência. São Paulo: Publifolha.

Corbin, J.; Strauss, A. (2008). Pesquisa qualitativa: técnicas e procedimentos para o desenvolvimento de teoria fundamentada ( $2^{\mathrm{a}}$ ed.). (Rocha, L. de O. da. Trad.). Porto Alegre: Artmed.

Resolução N.o 021/2015/CS-IFB (2015). Aprova o plano de curso do curso técnico em eventos integrado ao ensino 
médio e autoriza seu funcionamento. Instituto Federal de Brasília. Ministério da Educação.

Lima, L. O. (1979). Escola no Futuro. Petrópolis: Vozes, 2aㅗ edição.

Pedroza, R. L. S. (2005). O desenvolvimento da pessoa e o ensino-aprendizado. In: Pulino, L. H. (Ed.), Aprendizagem e a prática do professor. São Paulo: Modena. Brasília: UnB.

Queiroz, A. W. (2018). IFB em Transição. In: Instituto Federal da Brasília (Ed.), Relato de Experiências Integradoras Exitosas. Brasília: IFB.

Weller, W.; Gauche, R. (2017). Ensino médio em debate: currículo, avaliação e formação integral. Brasília: UnB.

Recebido: 15 de maio de 2019

Aprovado: 25 de setembro de 2019 